\title{
AVALIAÇÃO EMPÍRICA DA SEMELHANÇA DE CHOQUES E SIMETRIA NA FLUTUAÇÃO ECONÔMICA NA ZONA DO EURO: UMA ANÁLISE UTILIZANDO UM MODELO FAVAR
}

\author{
Jacqueline Maria Souza Araújo * \\ Elcyon Caiado Rocha Lima ${ }^{\dagger}$ \\ Luiz Fernando de Paula $\ddagger$
}

\begin{abstract}
Resumo
Este artigo analisa as semelhanças das respostas dos países da Zona do Euro aos choques na política monetária e no câmbio e investiga a simetria das flutuações do nível de atividade por meio da análise da importância relativa da resposta do crescimento do PIB aos choques comum e específico identificados pelo modelo FAVAR utilizado. A importância do choque comum nos diversos países fornece uma medida do grau de integração dos membros da Zona do Euro. Os resultados encontrados apontam para a existência de uma maior integração entre as grandes economias da Zona do Euro e menor integração para as menores economias.
\end{abstract}

Palavras-chave: Zona do Euro; simetria nas flutuações do produto (PIB); Vetor Autorregressivo Aumentado por Fatores Dinâmicos (FAVAR).

\begin{abstract}
This paper aims at analyzing the similarities of the responses of countries in the Eurozone to shocks in the monetary policy and exchange rate policy and to investigate the symmetry of fluctuations in the level of activity by analyzing the relative importance of the response of GDP growth in these countries to common and specific shocks identified by a FAVAR model. The importance of the common shocks provides a measure of the degree of integration of several members of the Eurozone. The results show the existence of greater integration among the major economies of the Eurozone and lesser integration among the small economies.
\end{abstract}

Keywords: Eurozone; symmetry of fluctuations of GDP; Factor-Augmented Vector Autoregression (FAVAR).

JEL classification: C22, F15.

DOI: http://dx.doi .org/10.11606/1980-5330/ea168733

\footnotetext{
* Mestre em Ciências Econômicas pela Universidade do Estado do Rio de Janeiro - UERJ. E-mail: araujojackie@hotmail.com.

${ }^{\dagger}$ Professor Associado da Faculdade de Ciências Econômicas da Universidade do Estado do Rio de Janeiro (FCE/UERJ). E-mail: elcyon.lima@uerj.br.

‡ Professor Titular da FCE/UERJ e do IESP/UERJ e Pesquisador do CNPq. E-mail: luizfpaula@terra.com.br.
} 


\section{Introdução}

A implementação da Zona do Euro tem sido alvo de ampla pesquisa e debate ao longo dos últimos anos (Bayoumi \& Eichengreen 1992, Frankel \& Rose 1998, Eickmeier 2006, Boivin et al. 2008). A crise da dívida soberana, deflagrada em 2009, desenvolveu-se como resultado do aumento do endividamento do governo na tentativa de resgatar o sistema bancário Europeu em resposta à desaceleração das economias da região que foram profundamente afetadas pela queda acentuada nos preços dos ativos, desencadeada pelo estouro da bolha imobiliária norte-americana, no segmento do mercado conhecido como subprime. Esse episódio expôs as fragilidades da Zona do Euro enquanto união monetária, e a governança da política econômica na região, e despertou renovado interesse acerca da discussão sobre as condições necessárias para se formar uma área monetária ótima.

Os critérios necessários para se formar uma união monetária estão apoiados na Teoria de Áreas Monetárias Ótimas (AMO), Mundell (1961). Baseada em seu trabalho pioneiro, que inicialmente destacou a mobilidade dos fatores de produção, especialmente a mobilidade da mão de obra, como propriedade essencial na formação de uma área monetária ótima, aponta-se para a importância da flexibilidade dos preços e dos salários como mecanismos de ajustamento a choques de demanda idiossincráticos. McKinnon (1963), por sua vez, acrescentou à teoria o grau de abertura ao comércio exterior, uma vez que um maior grau de abertura de uma economia ao exterior favoreceria a adoção de taxas de câmbio fixas, enquanto Kenen (1969) contribuiu com a importância da diversificação na estrutura produtiva das economias e com a relevância do federalismo fiscal. Esse conjunto de critérios formam, assim, o núcleo teórico clássico de AMO.

Ao longo do tempo, o arcabouço analítico subjacente à teoria de AMO foi sendo aprimorado e ampliado, emergindo daí uma nova fase da teoria. Os desenvolvimentos recentes envolvem a credibilidade das autoridades monetárias, incorporada por Kydland \& Prescott (1977) e Barro \& Gordon (1983); a eficiência da política monetária, introduzida por Artis (1991); as instituições do mercado de trabalho, sugerida por De Grauwe (1992); a eficácia dos ajustamentos cambiais, apontada por Tavlas (1993); a natureza dos choques, incluída por Buiter (1995) e a hipótese da especialização, defendida por Krugman (1993) em contraste com a hipótese da endogeneidade, proposta por Frankel \& Rose (1998), entre outras contribuições. Autores como Eichengreen (1993) e Rogoff (2001) enfatizam os custos dos países com ciclos de negócios não sincronizados e sem mecanismos compensatórios (como uma política fiscal compensatória) para abrirem mão de sua política monetária para um banco central comum.

Em relação ao último ponto desenvolveram-se duas visões antagônicas, com implicações diferentes para a implementação das uniões monetárias: $a$ hipótese da especialização que argumenta que uma maior integração comercial promoverá uma maior especialização setorial, tornando os choques mais assimétricos, conduzindo à menor convergência dos ciclos econômicos e, portanto, menor desejabilidade na formação de uniões monetárias (Krugman 1993); e a hipótese da endogeneidade das AMO, que defende que uma maior integração comercial induzirá uma maior convergência nas flutuações do produto e, portanto, maiores benefícios líquidos na formação de uniões monetárias, uma vez que o aumento esperado nos fluxos comerciais entre os membros da união 
monetária tornaria os ciclos econômicos mais sincronizados (Frankel \& Rose 1998) $)^{1}$.

Este artigo objetiva contribuir para avaliação da integração dos países da Zona do Euro, analisando as semelhanças das respostas dos países da Zona do Euro aos choques na política monetária e no câmbio e investigando a simetria das flutuações na taxa de crescimento do nível de atividade na região por meio da análise da importância relativa da resposta do crescimento do PIB desses países aos choques comum e específico identificados pelo modelo FAVAR utilizado. Esse modelo é estimado por meio de um método Bayesiano com prioris de Litterman (1986).

A importância do choque comum (relativamente ao específico) nos diversos países fornece uma medida do grau de integração dos diversos membros da Zona do Euro. Se o movimento do produto de um país-membro apresentar uma menor sincronia com o movimento do produto da região, a política monetária comum poderá acentuar as flutuações do produto nesse país, em vez de atenuá-las. Por outro lado, se o movimento do produto de um país-membro de uma união monetária apresentar uma maior sincronia com o movimento do produto da união, a adoção de uma política monetária e cambial comum, conduzida por um banco central único, será um substituto muito próximo da política monetária e cambial própria daquele país. Para o propósito deste artigo, entende-se por integração a semelhança nos movimentos comuns do produto: um país estará mais integrado quando a resposta ao choque comum for relativamente maior que a resposta ao choque específico.

Mais especificamente, este artigo pretende responder às seguintes questões: (i) Como os países da Zona do Euro respondem a um choque de política monetária e a um choque da taxa de câmbio? (ii) Qual a importância relativa de um choque comum e de um choque idiossincrático (específico)? (iii) Diante dos resultados obtidos, o que se pode concluir a respeito dos movimentos comuns do produto (integração) dos países da Zona do Euro?

Para tanto, o artigo utiliza um modelo de Vetor Autorregressivo Aumentado por Fatores Dinâmicos (FAVAR), com 125 variáveis econômicas e financeiras dos 17 países membros da União Monetária Europeia (UME) e dados trimestrais para o período 1999:1 a 2013:1. O FAVAR é particularmente apropriado por permitir sumariar um amplo conjunto de informações em um pequeno número de fatores dinâmicos, o que torna o modelo parcimonioso.

Além desta introdução, o artigo está organizado da seguinte forma: a Seção 2 efetua uma breve revisão da literatura empírica. A Seção 3 descreve brevemente os dados utilizados. A Seção 4 detalha a metodologia utilizada. Já a Seção 5 descreve e avalia os resultados obtidos. Por fim, a Seção 6 efetua uma síntese do artigo.

\section{Breve Revisão da Literatura Empírica}

Esta seção realiza uma breve revisão da literatura de trabalhos empíricos que buscaram em sua metodologia estimar choques comuns e/ou idiossincráticos sobre os países membros da Zona do Euro, bem como investigar o grau de convergência entre esses países.

\footnotetext{
${ }^{1}$ Clark \& Wincoop (2001) e Baxter \& Kouparitsas (2005) também encontraram uma associação positiva entre comércio bilateral e correlação dos ciclos de negócios.
} 
Bayoumi \& Eichengreen (1992) e Eichengreen (1993) usaram um VAR Estrutural para identificar choques de oferta e de demanda na Europa e para analisar as respostas dos países da Comunidade Europeia (CE). Fizeram o mesmo exercício para regiões dos EUA, usado como padrão de referência de uma AMO, e compararam os resultados da CE com os EUA. O período analisado foi de 1960 a 1988, ou seja, pré-UEM. A proposta era estudar se os choques da CE se tornaram mais correlacionados como resultado da convergência de políticas macroeconômicas e avaliar a viabilidade da formação de uma área monetária ótima na Europa. Com efeito, tanto a CE como os EUA estavam divididos entre um "centro" de regiões caracterizadas por um comportamento relativamente simétrico e uma "periferia", cujos choques eram mais fracamente correlacionados com os experimentados pelo "centro". Os resultados dos choques de demanda foram relativamente maiores nas regiões dos EUA comparados com os países da CE, sugerindo a maior especialização dos últimos e, portanto, a maior fragilidade destes frente a outras fontes de choques. Concluíram que a resposta aos choques foi significativamente mais idiossincrática entre os países membros da Comunidade Europeia (CE) do que entre as regiões dos EUA, indicando que a CE iria encontrar mais dificuldade para funcionar como uma união monetária. Encontraram pequena evidência de convergência entre o "centro" e a "periferia" da CE ao longo do tempo. As funções de impulso resposta indicaram que os países da CE apresentaram respostas mais lentas aos choques do que as regiões dos EUA, o que os autores presumiram ser explicado pela baixa mobilidade dos fatores.

Eickmeier (2006), por sua vez, estimou o tamanho e a persistência de comovimentos entre variáveis econômicas (ciclo de negócios) e a heterogeneidade (dispersão) na área do Euro e seus determinantes no período de 1982 a 2003. Mais precisamente, buscou responder às seguintes perguntas: (i) Quantos fatores comuns ou choques orientavam a economia na área do Euro? (ii) A origem da não estacionariedade das principais variáveis macroeconômicas dos países da UEM devia-se a choques comuns, idiossincráticos ou ambos? (iii) A heterogeneidade entre o desenvolvimento econômico de cada país era causada por choques idiossincráticos ou por choques comuns que se disseminavam de forma assimétrica? Para responder essas e outras questões utilizou a abordagem PANIC (Panel Analysis of Nonstationarity in Idiosyncratic and Common Components), que permitiu estimar os fatores comuns e os componentes idiossincráticos, estacionários e não estacionários, e avaliar o grau de persistência destes. Esse instrumental foi complementado com um modelo de fator dinâmico estrutural, que permitiu fazer uma análise estrutural, isto é, identificar choques estruturais comuns e avaliar seus mecanismos de propagação através do sistema. Os principais resultados encontrados foram: (i) identificação de cinco tendências comuns que orientavam a economia na área do Euro, sendo quatro fatores domésticos e um externo, a saber: dois choques de oferta (produtividade e oferta de trabalho), um choque de demanda, um choque de política monetária, e um choque nos EUA; (ii) a fonte da não estacionariedade das principais variáveis macroeconômicas devia-se a choques comuns e idiossincráticos; (iii) uma dispersão menor no desenvolvimento econômico entre os países era devida a choques idiossincráticos, enquanto que a principal força que explicava uma dispersão maior era a propagação assimétrica de choques comuns. A autora concluiu que, apesar dos países membros da UEM estarem intimamente ligados por meio do comércio e dos mercados financeiros, o comovimento econômico entre eles ainda estava longe de ser perfeito e 
continuava a persistir a heterogeneidade dos movimentos de produto e preços entre cada país.

Boivin et al. (2008) buscaram caracterizar o mecanismo de transmissão da política monetária na Zona do Euro e entre seus membros, ilustrando como esse mecanismo havia mudado com a introdução do Euro. A ideia geral é decompor as flutuações em séries individuais em um componente determinado por flutuações comuns na Zona do Euro, e um componente que é específico para a série considerada no trabalho. Em particular, objetiva-se também explicar as diferenças observadas ao longo do tempo e entre países em resposta às principais variáveis macroeconômicas. Para tanto utilizaram um Vetor Autorregressivo Aumentado por Fatores Dinâmicos (FAVAR), a partir do trabalho de Bernanke et al. (2005), com um painel balanceado de 245 séries trimestrais, para o período de 1980:1 a 2007:3. Os autores encontraram importante heterogeneidade de respostas entre os países frente aos choques antes do lançamento do Euro. Em particular, encontraram que um choque na taxa de juros alemã provocou fortes efeitos sobre as taxas de juros de longo prazo na Itália e na Espanha, contribuindo para uma forte contração do consumo nesses dois países. De acordo com suas estimativas, a criação do Euro contribuiu para uma maior homogeneidade nos mecanismos de transmissão da política monetária entre os países membros da Zona do Euro e para uma redução generalizada nos efeitos desses choques. Em particular, as taxas de juros de longo prazo, o investimento, o produto e o emprego responderam em menor intensidade aos choques de taxas de juros de curto prazo no novo regime de política monetária, enquanto o comércio e a taxa de câmbio real efetiva responderam de forma mais intensa. Os autores encontraram que o consumo privado e o investimento são mais estáveis na Itália e na Espanha, em parte porque as taxas de juros de longo prazo estavam mais efetivamente ancoradas nesses países desde o início da união monetária. Argumentaram ainda que essas mudanças são explicadas não somente pela mudança no regime monetário, mas também pela atuação do BCE. O modelo prediz que, ao remover o risco de taxa de câmbio entre os países membros da união, como resultado da fixação das taxas de câmbio através da união monetária, e, por ter um Banco Central mais decisivamente focado na estabilização da inflação e do produto, o impacto de choques monetários sobre a atividade econômica tem se reduzido.

Cabe mencionar, ainda, o trabalho de Gonçalves et al. (2009), que ainda que não objetive estimar choques (comuns e idiossincráticos) entre os países membros da Zona do Euro, contribui para investigação sobre a correlação de ciclos de negócios entre os países membros da União Monetária Europeia (UME) depois da implementação do Euro em comparação a outros países da OECD. Para tanto, os autores utilizam uma técnica simples de diferenças em diferenças para uma base de dados de 22 países do OECD, para o período de 1980 a 2007, no qual 12 vieram a aderir a UME, de modo a avaliar se a maior correlação de ciclos entre pares de países da Zona do Euro depois de 1999 pode ser atribuída a adoção da moeda comum. Os resultados obtidos na estimativa realizada pelos autores sugerem que a adoção do Euro tem tornado os ciclos econômicos mais correlacionados entre os pares dos países membros da UME. Acrescentam, ainda, que o "efeito Euro" não é consequência de um comércio maior entre os países que têm a mesma moeda comum, uma vez que mudanças no comércio externo parecem ter contribuído negativamente para a correlação bilateral entre os ciclos. Alternativamente, esse resultado parece ser relacionado diretamente à política monetária comum, e não à sua 
influência sobre os fluxos comerciais bilaterais. Portanto, a existência de choques monetários comuns aparece como uma das principais razões por trás da maior sincronização de ciclos econômicos entre os países da UME.

Este artigo objetiva contribuir para a análise empírica do grau de integração dos países da Zona do Euro ao utilizar uma metodologia que permite o uso de um amplo conjunto de variáveis e ao identificar o grau de simetria das flutuações na taxa de crescimento do nível de atividade dos membros da UME por meio da identificação dos choques comuns e específicos. Esse grau de integração pode ser mais profundamente verificado observando-se a simetria das respostas desses países aos choques exógenos nas políticas monetária e fiscal. Esses choques, neste artigo, foram identificados através da imposição de restrições nas funções impulso-resposta.

O artigo também inova, em relação à literatura descrita nesta seção, ao utilizar uma metodologia que permite incorporar uma quantidade muito grande de informação sem que isso implique em perda substantiva de graus de liberdade na estimação do modelo. Ademais, faz uma inovação metodológica ao incorporar na análise, do grau de integração dos países da Zona do Euro, os impactos dos choques comuns e específicos no nível de atividade dos países.

Tendo como base esta breve resenha da literatura empírica, desconhecemos a utilização do modelo FAVAR em análise igual à proposta por este artigo para identificação de choques comuns e específicos. O modelo foi estimado através de um método Bayesiano desenvolvido para incorporar prioris de Litterman (1986).

\section{Dados}

A frequência dos dados utilizados é trimestral e o período analisado corresponde ao primeiro trimestre de 1999 até o primeiro trimestre de 2013. O início da amostra coincide com a adoção da moeda comum, o Euro. Foram utilizados todos os dados que estavam disponíveis, a partir de 1999:1 e até data da elaboração inicial do artigo. Foram utilizadas 56 observações para cada variável incluída no modelo. Os dados incluem variáveis econômicas e financeiras dos 17 países membros da Zona do Euro, a saber: Alemanha, Áustria, Bélgica, Chipre, Eslováquia, Eslovênia, Espanha, Estônia, Finlândia, França, Grécia, Holanda, Irlanda, Itália, Luxemburgo, Malta e Portugal. Para obter os fatores dinâmicos do FAVAR, foram utilizadas 125 séries financeiras e macroeconômicas coletadas em diversas fontes ${ }^{2}$. Foram feitas as seguintes transformações das variáveis: 1) O PIB, a produção industrial, as exportações e as importações forem medidos em termos de taxas anuais de variação acumuladas nos últimos doze meses; 2) O déficit primário e a dívida foram expressos em percentuais do PIB de cada país; 3) As taxas de inflação de cada país e da Zona do Euro medem os seus valores acumulados nos últimos doze meses; 4) As taxas de juros utilizadas se referem aos seus valores trimestrais (utilizando médias ponderadas por dias de vigência quando for o caso) e foram expressas em termos anuais. Deve ser ressaltado que as séries de dívidas dos países fo-

\footnotetext{
${ }^{2}$ Foram usadas as seguintes fontes: PIB (Eurostat), déficit primário (OECD), Taxa de Câmbio US $\$ \mathrm{x} € \$$ (BCE), inflação - índice de preços ao consumidor (Eurostat), juros de longo prazo de títulos da dívida soberana (FMI), taxa de juros do Federal Reserve (FED), exportações e importações (FMI), taxa de desemprego (FMI) e produção industrial (FMI).
} 
ram excluídas na estimação final do modelo, pois dispúnhamos de dados só a partir de 2000.

As séries que se mostraram não estacionárias foram diferenciadas até que se tornassem estacionárias. Os resultados dos testes de raízes unitárias foram obtidos utilizando-se o software Eviews e encontram-se na Tabela A.1, em anexo.

O FAVAR contém também variáveis cujas informações não foram condensadas em fatores dinâmicos e que foram utilizadas para impor restrições de sinais nas funções impulso-resposta. Escolheram-se as seguintes variáveis: taxa de juros do Banco Central Europeu (BCE rate), taxa de juros de curto prazo da Comunidade Europeia (CE), taxa de inflação, a taxa de câmbio nominal (US\$/€\$) e o PIB da CE.

\section{Metodologia}

\subsection{O Modelo}

Suponha que a dinâmica conjunta de $\left(F_{t}, Y_{t}\right)$, onde o vetor $Y_{t}$ contém instrumentos da Política Monetária e Cambial do Banco Central Europeu, possa ser descrita pelas Equações (1) e (2) a seguir:

$$
\left[\begin{array}{c}
F_{t} \\
Y_{t}
\end{array}\right]=\Phi(L)\left[\begin{array}{c}
F_{t-1} \\
Y_{t-1}
\end{array}\right]+D J+v_{t}
$$

Em que : $\Phi(L)$ é um polinômio do operador de defasagens $L$ de ordem finita $p$; $D$ é uma matriz $(M+K) \times h$ de parâmetros de variáveis exógenas; $J$ é um vetor $h \times 1$ de variáveis exógenas. O termo de erro, $v_{t}$, tem média zero e matriz de covariância $Q$.

Admitimos que as séries de tempo informativas $X_{t}$ estão relacionadas aos fatores dinâmicos não observáveis, $F_{t}$, bem como às variáveis observáveis, $Y_{t}$, por meio da seguinte equação:

$$
X_{t}=\Lambda^{f} F_{t}+\Lambda^{y} Y_{t}+e_{t}
$$

Em que $\Lambda^{f}$ é uma matriz de cargas fatoriais $N \times K, \Lambda^{y}$ é uma matriz de cargas fatoriais $N \times M$ e $e_{t}$ é um vetor dos erros $N \times 1$, com média zero e não correlacionado contemporânea e serialmente. A Equação (2) captura a ideia de que ambos, $Y_{t}$ e $F_{t}$, que em geral podem ser correlacionados, representam as forças comuns que impulsionam a dinâmica de $X_{t}$. Condicional em $Y_{t}$, os $X_{t}$ são, portanto, medidas ruidosas dos fatores observados subjacentes, $F_{t}$. Na Equação (2), $X_{t}$ depende apenas dos valores correntes e não dos valores defasados dos fatores dinâmicos. No entanto, essa formulação não é restritiva na prática, já que $F_{t}$ pode ser interpretado como arbitrário, incluindo defasagens dos fatores fundamentais. Stock \& Watson (1999) referem-se à Equação (2) sem as variáveis observáveis - como um modelo de fator dinâmico.

O modelo foi estimado através de um procedimento Bayesiano que utiliza o amostrador de Gibbs. Este é utilizado para obter uma amostra das distribuições a posteriori e é definido, essencialmente, como um esquema iterativo de amostragem de uma cadeia de Markov cujo núcleo de transição é formado pelas distribuições condicionais Gamerman (1996). Em uma análise Bayesiana as informações existentes sobre os parâmetros de interesse são incorporadas 
no modelo por meio das distribuições a priori desses parâmetros. O modelo em espaço de estados:

$$
\begin{gathered}
{\left[\begin{array}{c}
X_{t} \\
Y_{t}
\end{array}\right]=\left[\begin{array}{cc}
\Lambda^{f} & \Lambda^{y} \\
0 & I
\end{array}\right]\left[\begin{array}{c}
F_{t} \\
Y_{t}
\end{array}\right]+\left[\begin{array}{c}
e_{t} \\
0
\end{array}\right]} \\
{\left[\begin{array}{c}
F_{t} \\
Y_{t}
\end{array}\right]=\Phi(L)\left[\begin{array}{c}
F_{t-1} \\
Y_{t-1}
\end{array}\right]+D J+v_{t}}
\end{gathered}
$$

Em que $Y_{t}$ é um vetor $M \times 1$ de variáveis econômicas observáveis, cujas propriedades dinâmicas são de grande interesse; $F_{t}$ é um vetor $K \times 1$ de fatores dinâmicos não observados; $D$ é uma matriz $(M+K) \times h$ de parâmetros de variáveis exógenas; $J$ é um vetor $h \times 1$ de variáveis exógenas e $X_{t}$ é um vetor $N \times 1$ de séries temporais que contém informação sobre os fatores dinâmicos não observados. As cargas $\Lambda^{f}$ e $\Lambda^{y}$ são restritas, conforme discutido anteriormente. O vetor de erros $e_{t} \sim N(0 ; R)$ e $v_{t} \sim N(0 ; Q)$ são $N \times 1$ e $(K+M) \times 1$, respectivamente, e têm as seguintes distribuições $e_{t}(0 ; R)$ e $v_{t}(0 ; Q)$, com $e_{t}$ e $v_{t}$ independentes e $R$ diagonal.

A Equação (3) é a equação da medida ou das observações, enquanto (4) é a equação de transição.

\subsection{O Método de Estimação}

Resumidamente, seja $Z_{t}=\left(X_{t}, Y_{t}\right), \epsilon_{t}=\left(e_{t}, 0\right)$ e $G_{t}=\left(F_{t}, Y_{t}\right)$, então as Equações (3) e (4) podem ser reescritas como:

$$
\begin{gathered}
Z_{t}=\Lambda G_{t}+\epsilon_{t} \\
G_{t}=\Phi(L) G_{t-1}+D J+v_{t}
\end{gathered}
$$

Note que $\Lambda$ tem como parâmetros desconhecidos as matrizes de cargas fatoriais, compostas por $\Lambda^{f}$ e $\Lambda^{y}$, e $P=\operatorname{cov}\left(\epsilon_{t}, \epsilon_{t}^{\prime}\right)$ s é a matriz de covariância de $\epsilon_{t}=\left(e_{t}, 0\right)$.

A Equação (6) pode ser expressa em sua versão estrutural, ou seja:

$$
H G_{t}=H \Phi(L) G_{t-1}+H D J+H v_{t}
$$

Em que: $H$ é de posto completo e escolhida de tal forma que pondo-se $u_{t}=H v_{t}, \operatorname{cov}\left(u_{t}\right)=I$. Seja $H \Phi(L)=C_{1} L+\ldots+C_{p} L^{p}$ e $\psi=\left[C_{1}, \ldots C_{p} D\right]$.

Seja $x_{t}=\left[G_{t-1} G_{t-2} \ldots G_{t-p} J\right]^{\prime}$, admitindo que o VAR tenha $p$ defasagens (no nosso artigo $p=4$ e é maior do que o número de defasagens que seria escolhido utilizando-se um procedimento clássico de estimação e critérios de informação). Então a Equação (6) na forma estrutural pode ser escrita como:

$$
G_{t}^{\prime} H^{\prime}=x_{t}^{\prime} \psi^{\prime}+u_{t}^{\prime}
$$

Seguindo um enfoque Bayesiano, os parâmetros do modelo $\theta=(H, \Phi(L), D$, $\left.\Lambda^{f}, \Lambda^{y}, R, Q\right)$ serão tratados como variáveis aleatórias. A estimação desses parâmetros e dos fatores não observados $F_{t}$ é realizada por um procedimento conhecido na literatura como multimovimento do amostrador de Gibbs (Carter \& Kohn 1994). 
Seja $\tilde{X_{T}}=\left(X_{1}, X_{2}, \ldots, X_{T}\right)$ a história de $X$ entre o período 1 e o período $T$. Então pode-se definir $\tilde{F_{T}}=\left(F_{1}, F_{2}, \ldots, F_{T}\right)$. A análise Bayesiana trata os parâmetros do modelo como variáveis aleatórias, e o que desejamos é obter as densidades marginais a posteriori de $\tilde{F_{T}}$ e $\theta$, respectivamente:

$$
\begin{aligned}
& p\left(\tilde{F_{T}}\right)=\int p\left(\tilde{F_{T}}, \theta\right) d \theta \\
& p(\theta)=\int p\left(\tilde{F_{T}}, \theta\right) d \tilde{F_{T}}
\end{aligned}
$$

Onde $p\left(\tilde{F_{T}}, \theta\right)$ é a densidade a posteriori conjunta de $\tilde{F_{T}}$ e $\theta$ e as integrais são tomadas em relação a $\tilde{F_{T}}$ e $\theta$, respectivamente. Dadas essas densidades marginais a posteriori, a estimação de $\tilde{F_{T}}$ e $\theta$ pode ser obtida pela moda das distribuições empíricas correspondentes às densidades especificadas pelas Equações (8) e (9).

Para obter extrações dessas densidades foi aplicado o método de multimovimento do amostrador de Gibbs para o modelo em espaço-de-estados dado pelas Equações (5) e (7). Seja $\beta=\left(\Lambda^{f}, \Lambda^{y}, R\right)$ e $\xi=(H \Phi(L), D, Q)$. Portanto, $\theta=(\xi, \beta)$. No que se segue o $(s)$ indica simulação $s$. As extrações dessas densidades são feitas através de dois passos: I) Dados $\tilde{Z_{T}}$ e $\theta^{s-1}$ extrair $\tilde{F}_{T}^{(s)}$ e $\beta^{(s)}$; II) Dados $\tilde{Z}_{T}, \tilde{F}_{T}^{(s)}$ extrair $\psi^{(s)}$ e $H^{(s)}$ e, portanto, $\xi^{(s)}$.

Para descrições detalhadas dos procedimentos adotados nos passos I) e II) ver, respectivamente, Almeida et al. (2012) e Lima et al. (2011). Os procedimentos de simulação adotados nos passos I) e II) foram desenvolvidos, respectivamente, por Bernanke et al. (2005) e por Waggoner \& Zha (2003).

O passo II é mais complexo e será ligeiramente descrito a seguir. Considerando como dados $\tilde{F}_{T}^{(s)}$ e $\tilde{Z}_{T}$, e utilizando a Equação (7), podemos utilizar o algoritmo proposto por Waggoner \& Zha (2003) (descrito detalhadamente em Lima et al. (2011)) para obter, por meio de um procedimento Bayesiano com prioris de Litterman (1986), uma extração "s" para $\psi$ e $H, \psi^{(s)}$ e $H^{(s)}$. Nós, como os autores citados, utilizamos quatro hiperparâmetros $\lambda_{1}, \lambda_{2}, \lambda_{3}$ e $\lambda_{4}$ para as prioris. O parâmetro $\lambda_{1}$ mede o grau de aperto (tightness) geral, em torno das médias das prioris, para todos os coeficientes, inclusive para os parâmetros dos valores contemporâneos das variáveis. O parâmetro $\lambda_{2}$ mede o aperto relativo, em torno das médias das prioris, para os coeficientes dos valores defasados das variáveis. O parâmetro $\lambda_{3}$ mede o aperto relativo para o termo constante e o parâmetro $\lambda_{4}$ mede a progressão do aperto à medida que aumenta a defasagem da variável. No nosso artigo os seus valores foram fixados em 0,5, 0,25, 10 e 2. O número de defasagens das Equações (6) e (7) foi fixado arbitrariamente em 4 . Esse número de defasagens é maior do que o sugerido por critérios de informação utilizando-se procedimentos clássicos de estimação.

Obtendo uma Extração da Função Impulso Resposta que Satisfaz às Restrições de Sinais

- Para cada simulação " $s$ ", descrita anteriormente, faça a extração de uma matriz $\tilde{W}$ de uma distribuição normal padrão independente de dimensão $r \times r(r=$ número de variáveis endógenas do BVAR) e seja $\tilde{W}=\tilde{Q} \tilde{R}$ 
uma decomposição QR de $\tilde{W}$ com diagonal $\tilde{R}$ normalizada para ser positiva;

- Seja $H^{(s)}=H^{(s)} \tilde{Q}$. Compute a função impulse resposta $I R F^{(s)}$ dados $H^{(s)}$ e $\psi^{(s)}$.

- Se a $I R F^{(s)}$ satisfaz às restrições de sinais ela é mantida e descartada em caso contrário.

Após um número grande de simulações são mantidas todas as simulações das Funções Impulso Resposta que satisfazem à restrição de sinal.

\section{A Identificação dos Choques}

As restrições de sinais foram extraídas do modelo Mundell - Fleming estocástico dinâmico ${ }^{3}$. A Tabela $1^{4}$, a seguir, resume as restrições de sinais sobre as funções impulso-resposta utilizadas neste artigo para identificar os choques de política monetária e da taxa de câmbio real ${ }^{5}$.

Dadas as restrições impostas de acordo com a Tabela 1, após um choque "contracionista" de política monetária, a taxa de juros do BCE sobe, o nível de preços na Zona do Euro (ZE) diminui, a taxa de juros de curto prazo da ZE sobe, a taxa de câmbio nominal não diminui ou aumenta (valoriza), o produto da ZE, da Alemanha e da França não aumentam ou tendem a cair (restrições impostas às respostas de 1 a 5 passos à frente).

Ainda, após choque na taxa de câmbio, o nível de preços não cai (ou tende a aumentar), ocorre um aumento da taxa de câmbio nominal (US\$/€\$) e o produto da ZE, Alemanha e da França não diminuem ou aumentam (restrições impostas às respostas de 1 a 5 passos à frente).

Tabela 1: Restrições de sinais usadas para identificar o modelo FAVAR

\begin{tabular}{lcc}
\hline & \multicolumn{2}{c}{ Tipo de Choque } \\
Resposta das Variáveis & Política Monetária & Taxa de Câmbio \\
\hline Taxa de juros do BCE & $>0$ & Agnóstico \\
Inflação CE & $\leq 0$ & $\geq 0$ \\
Juros CP CE & $>0$ & Agnóstico \\
Taxa de câmbio nominal & $\geq 0$ & $<0$ \\
PIB CE & $\leq 0$ & $\geq 0$ \\
PIB Alemanha & $\leq 0$ & $\geq 0$ \\
PIB França & $\leq 0$ & $\geq 0$ \\
\hline
\end{tabular}

Fonte: Elaboração própria dos autores.

\footnotetext{
${ }^{3} \mathrm{O}$ modelo Mundell-Fleming estocástico dinâmico é idêntico ao apresentado em Lima et al. (2011).

${ }^{4} \mathrm{Na}$ Tabela 1 a sigla CE representa a Comunidade Europeia, aqui entendida como os países que compõem a Zona do Euro.

${ }^{5} \mathrm{O} \log$ da taxa de câmbio real é definido como $q_{t}=s_{t} p_{t}^{*}-p_{t}$, onde $s_{t}$ é o log da taxa de câmbio nominal e $p_{t}\left(p_{t}^{*}\right)$ é o log do nível geral de preços doméstico (estrangeiro). Foi assumido que o nível de preços estrangeiro é constante, de maneira que uma restrição sobre a taxa de câmbio real traduz-se em uma restrição sobre $s_{t}-p_{t}$.
} 
Obtendo uma Extração da Função Impulso Resposta dos Choque Específicos e Comuns

Considere a Equação (2) descrita anteriormente e apresentada novamente a seguir:

$$
X_{t}=\Lambda^{f} F_{t}+\Lambda^{y} Y_{t}+e_{t}
$$

Seja $C_{i, t}^{(s)}=\Lambda_{t}^{(s), f} F_{t}^{(s)}+\Lambda_{t}^{(s), y} Y_{t}$ o valor obtido para as duas primeiras parcelas da equação $i$, pertencente ao conjunto de Equações (2), na simulação " $s$ " do modelo no período $t$. Seja $e_{i, t}^{(s)}$ o valor do resíduo da equação $i$ na simulação " $s$ " no período $t$. A variável aleatória $C$ é uma combinação linear de todas as variáveis que afetam (ou podem afetar) o nível de atividade de todos os países da Zona do Euro.

Para cada simulação "s" para todos os parâmetros do modelo e para cada equação $i$ é estimada uma autorregressão de ordem $4^{6}(\operatorname{AR}(4))$ utilizando os valores de $C_{i, t}^{(s)}, t=1, \ldots, T$, e obtida a função impulso resposta dessa autorregressão utilizando um choque igual a um desvio padrão do resíduo. Esta é a função impulso-resposta do choque comum na simulação " $s$ ".

Para cada simulação " $s$ " para todos os parâmetros do modelo e para cada equação $i$ é estimada uma autorregressão utilizando os valores de $e_{i, t}^{(s)}, t=$ $1, \ldots, T$, e obtida a função impulso resposta dessa autorregressão utilizando um choque igual a um desvio padrão do resíduo. Esta é a função impulsoresposta do choque específico na simulação "s". A variável apenas afeta o nível de atividade do país " $i$ ".

\section{Resultados Empíricos}

As respostas das variáveis aos choques na política monetária e na taxa de câmbio, estimadas com restrições de sinais, são apresentadas na Figura 1. Nele, são apresentadas as medianas das respostas, bem como as bandas de probabilidade de $68 \%$ para um horizonte de 8 trimestres após os choques.

Neste artigo é analisada a semelhança nos movimentos do produto, isto é, a integração entre os países membros da Zona do Euro a partir de um amplo conjunto de variáveis, empregando-se um FAVAR com 125 variáveis. Foram identificados dois choques: um choque de política monetária e um choque sobre a taxa de câmbio. O modelo permitiu também identificar as respostas do PIB dos diversos países a um choque comum e a um choque idiossincrático, com o intuito de descobrir qual choque é mais relevante.

O choque de política monetária resultou em respostas parcialmente similares entre os países da Zona do Euro em termos da resposta do nível de atividade ou dos preços ou ambos. Um choque contracionista de política monetária apresentou resposta semelhante, ou seja, queda da inflação e do produto nos seguintes países: Alemanha, Bélgica, Espanha, França, Holanda, Irlanda, Itália e Luxemburgo. Portugal apresentou resposta apenas sobre o nível de preços, com queda da inflação. Alguns países apresentaram resposta só recessiva, com queda do produto: Áustria, Estônia, Eslovênia, Eslováquia, Finlândia e Grécia. Para os demais países (Chipre e Malta), não houve resposta

\footnotetext{
${ }^{6}$ Foi escolhido um número de defasagens maior do que a sugerida pelo critério de Schwarz. Preferiu-se pecar por excesso na escolha das defasagens. Deve ser mencionado, no entanto, que este número maior de defasagens não altera os resultados de forma significativa.
} 
Figura 1: Choque de política monetária e choque cambial
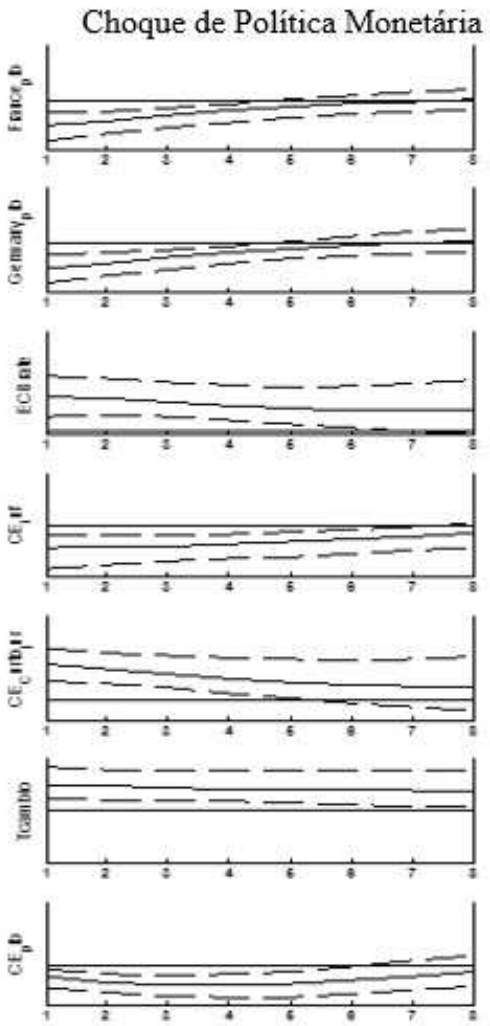

Choque Cambial
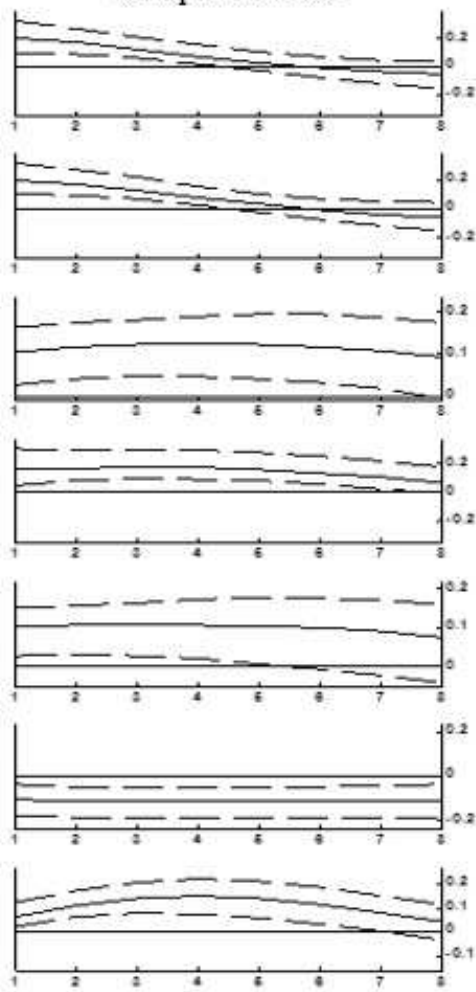

Fonte: Elaboração dos autores.

Legenda: France pib - PIB da França; Germany pib - PIB da Alemanha; ECB rate - taxa de juros do Banco Central Europeu; CE inf - inflação da Comunidade Europeia; CE curto jur - juros de curto prazo da Comunidade Europeia; Tcambio - Taxa de câmbio (US\$/€\$); CE pib - PIB da Comunidade Europeia.

significativa nem da inflação nem do nível de atividade. Os choques identificados de política monetária, na Zona do Euro, apresentam respostas (quando significativas) com os sinais esperados mas que não são estritamente iguais (homogêneas) entre os países. Esses resultados podem ser visualizados na Figura 2.

Considerando um choque exógeno de desvalorização do Euro, Alemanha, Bélgica, Espanha, Eslovênia, França, Finlândia, Irlanda, Itália, Luxemburgo, Holanda e Portugal apresentaram resposta semelhante, a saber, aumento do nível do produto e da inflação. Áustria, Estônia e Eslováquia apresentaram apenas aumento do nível do produto. Grécia apresentou apenas aumento da inflação. Todos esses resultados podem ser visualizadas na Figura 3. Os demais países não apresentaram resposta significativa.

De um modo geral nota-se uma perfeita sincronia na resposta de todos os países da Zona do Euro em relação ao choque cambial. Já no que se refere à política monetária, há sincronia em todos os países grandes, mas nota-se alguma assimetria entre eles em alguns países pequenos (Luxemburgo, Eslováquia, Eslovênia, Áustria, Grécia e Estônia), sendo que muitos destes são os que integraram mais recentemente a Zona do Euro. Isso parece indicar um alto grau 
Figura 2: Choque exógeno da política monetária
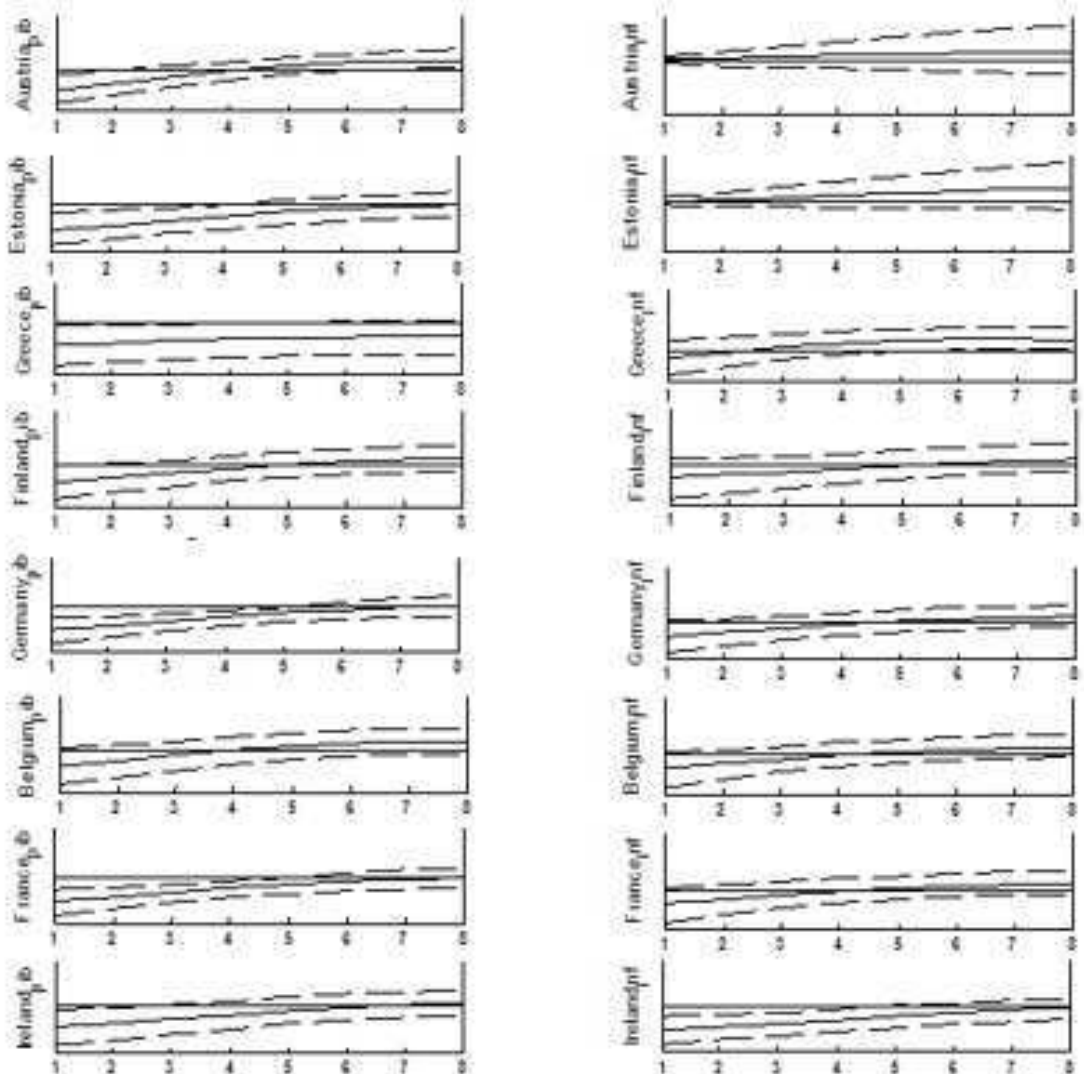

Fonte: Elaboração dos autores.

Legenda: Germany pib - PIB da Alemanha; Germany inf - inflação da Alemanha; Belgium pib PIB da Bélgica; Belgium inf - inflação da Bélgica; France pib - PIB da França; France inf inflação da França; Ireland pib - PIB da Irlanda; Ireland inf - inflação da Irlanda; Italy pib - PIB da Itália; Italy inf - inflação da Itália; Luxembourg pib - PIB de Luxemburgo; Luxembourg inf inflação de Luxemburgo; Netherlands pib - PIB da Holanda; Netherlands inf - inflação da Holanda; Spain pib - PIB da Espanha; Spain inf - inflação da Espanha; Portugal pib - PIB de Portugal; Portugal inf - inflação de Portugal; Slovak Republic pib - PIB da Eslováquia; Slovak Republic inf - inflação da Eslováquia; Austria pib - PIB da Áustria; Austria inf - inflação da Áustria; Estonia pib - PIB da Estônia; Estonia inf - inflação da Estônia; Greece pib - PIB da Grécia; Greece inf - inflação da Grécia; Finland pib - PIB da Finlândia; Finland inf - inflação da Finlândia. 
Figura 2: Choque exógeno da política monetária (continuação)
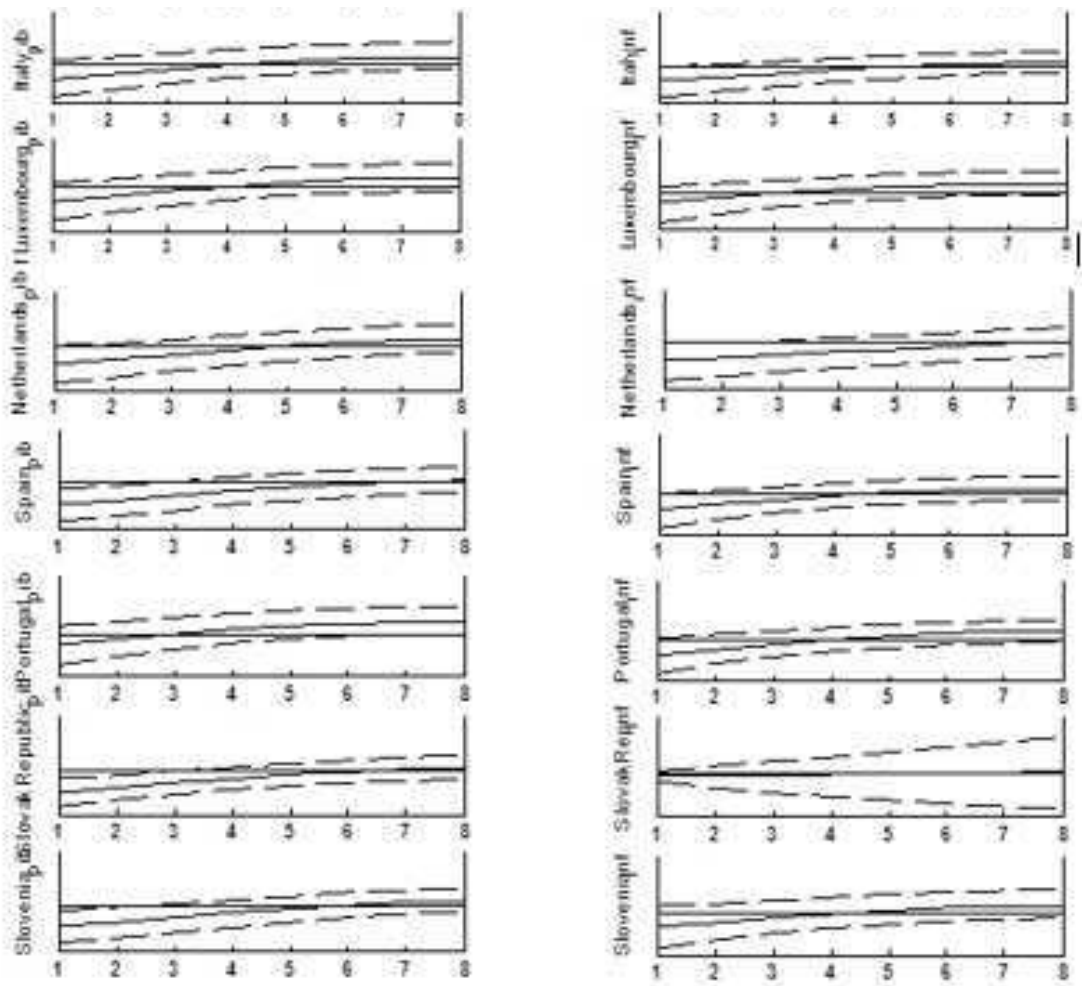

Fonte: Elaboração dos autores.

Legenda: Germany pib - PIB da Alemanha; Germany inf - inflação da Alemanha; Belgium pib PIB da Bélgica; Belgium inf - inflação da Bélgica; France pib - PIB da França; France inf inflação da França; Ireland pib - PIB da Irlanda; Ireland inf - inflação da Irlanda; Italy pib - PIB da Itália; Italy inf - inflação da Itália; Luxembourg pib - PIB de Luxemburgo; Luxembourg inf inflação de Luxemburgo; Netherlands pib - PIB da Holanda; Netherlands inf - inflação da Holanda; Spain pib - PIB da Espanha; Spain inf - inflação da Espanha; Portugal pib - PIB de Portugal; Portugal inf - inflação de Portugal; Slovak Republic pib - PIB da Eslováquia; Slovak Republic inf - inflação da Eslováquia; Austria pib - PIB da Áustria; Austria inf - inflação da Áustria; Estonia pib - PIB da Estônia; Estonia inf - inflação da Estônia; Greece pib - PIB da Grécia; Greece inf - inflação da Grécia; Finland pib - PIB da Finlândia; Finland inf - inflação da Finlândia.

de integração entre os países grandes e um menor grau de integração de vários países pequenos, sendo que muito deles ingressaram só recentemente.

Foram identificadas as respostas do PIB dos diversos países a um choque comum e a um choque específico. Quanto menor a importância relativa da resposta ao choque específico em relação ao choque comum, maior será a semelhança dos movimentos do produto nos diversos países e mais integrados deverão eles estar. Entende-se por choque específico ou idiossincrático aquele que, inicialmente, afeta adversamente apenas um país. O choque comum é aquele que afeta a economia como um todo, ou seja, afeta todos os países ao mesmo tempo.

Com relação à mensuração das respostas do PIB dos diversos países a um choque comum e a um choque idiossincrático, o modelo apresentou uma resposta ao choque comum maior e, portanto, mais relevante do que a resposta ao choque específico de cada país, para todos os países. 
Figura 3: Choque exógeno de desvalorização do Euro
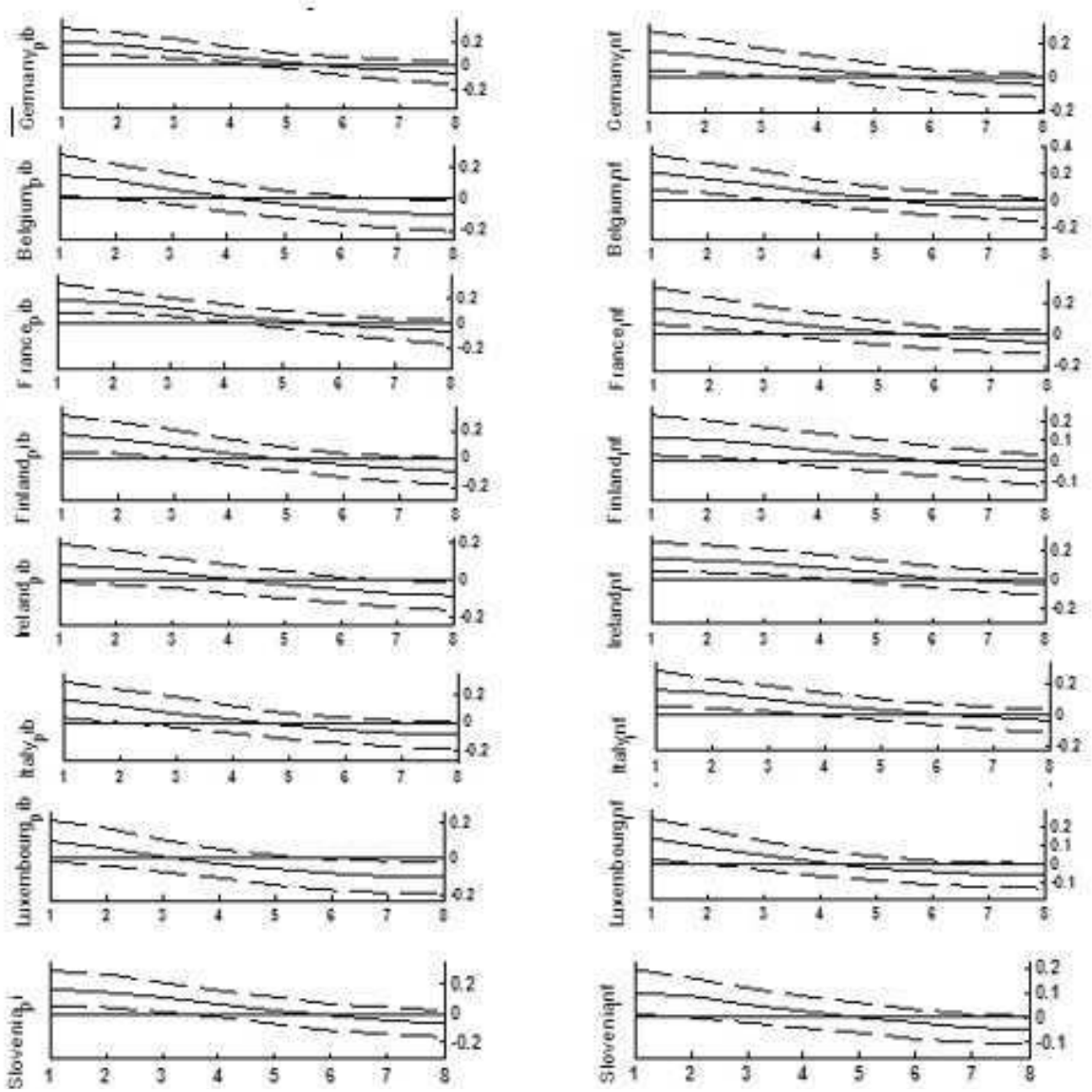

Fonte: Elaboração dos autores.

Legenda: Germany pib - PIB da Alemanha; Germany inf - inflação da Alemanha; Belgium pib PIB da Bélgica; Belgium inf - inflação da Bélgica; France pib - PIB da França; France inf inflação da França; Finland pib - PIB da Finlândia; Finland inf - inflação da Finlândia; Ireland pib - PIB da Irlanda; Ireland inf - inflação da Irlanda; Italy pib - PIB da Itália; Italy inf inflação da Itália; Luxembourg pib - PIB de Luxemburgo; Luxembourg inf - inflação de Luxemburgo; Slovenia pib - PIB da Eslovênia; Slovenia inf - inflação da Eslovênia; Spain pib PIB da Espanha; Spain inf - inflação da Espanha; Netherlands pib - PIB da Holanda;

Netherlands inf - inflação da Holanda; Portugal pib - PIB de Portugal; Portugal inf - inflação de Portugal; Austria pib - PIB da Áustria; Austria inf - inflação da Áustria; Slovak Republic pib PIB da Eslováquia; Slovak Republic inf - inflação da Eslováquia; Greece pib - PIB da Grécia; Greece inf - inflação da Grécia. 
Figura 3: Choque exógeno de desvalorização do Euro (continuação)
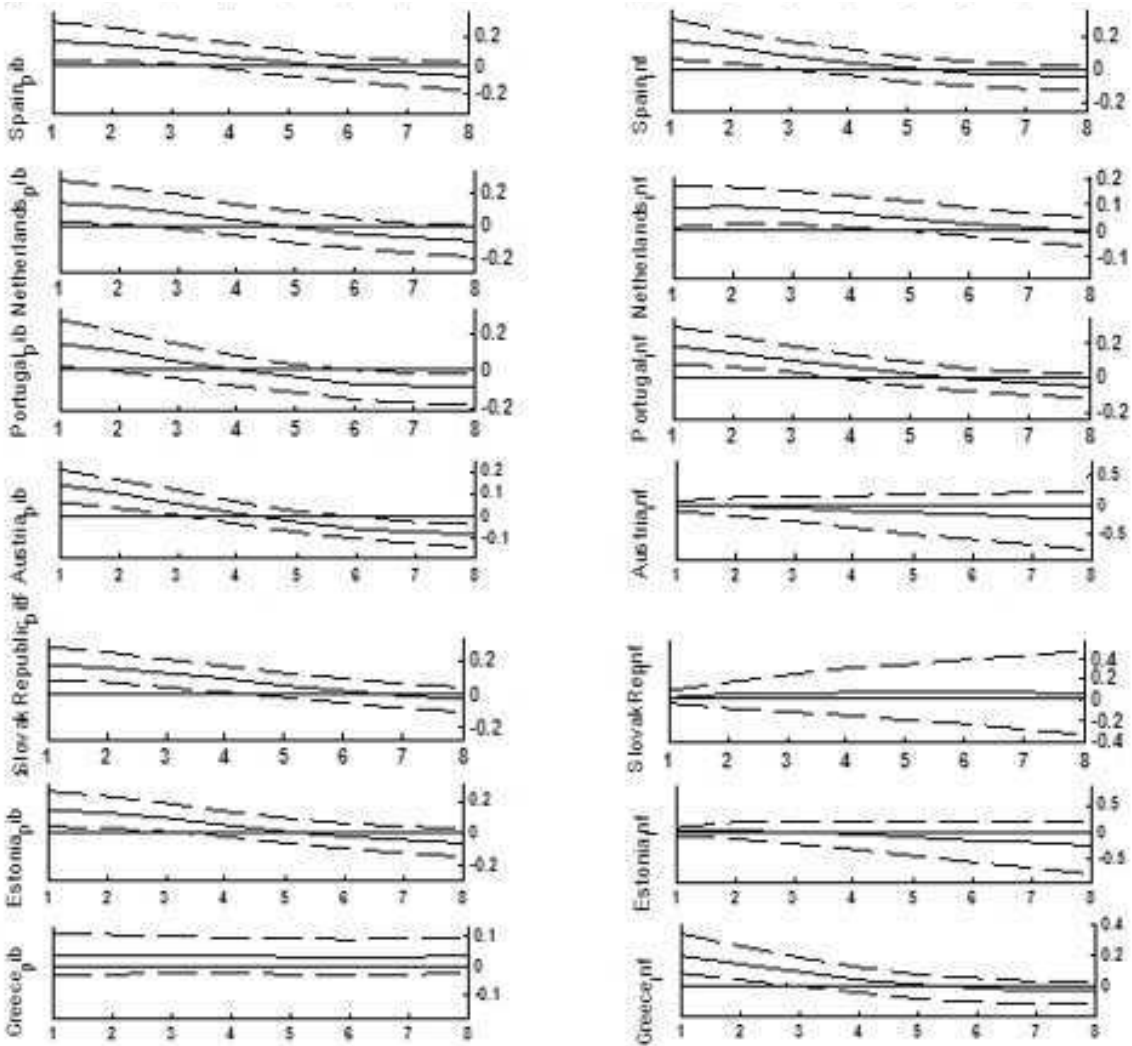

Fonte: Elaboração dos autores.

Legenda: Germany pib - PIB da Alemanha; Germany inf - inflação da Alemanha; Belgium pib PIB da Bélgica; Belgium inf - inflação da Bélgica; France pib - PIB da França; France inf inflação da França; Finland pib - PIB da Finlândia; Finland inf - inflação da Finlândia; Ireland pib - PIB da Irlanda; Ireland inf - inflação da Irlanda; Italy pib - PIB da Itália; Italy inf inflação da Itália; Luxembourg pib - PIB de Luxemburgo; Luxembourg inf - inflação de Luxemburgo; Slovenia pib - PIB da Eslovênia; Slovenia inf - inflação da Eslovênia; Spain pib PIB da Espanha; Spain inf - inflação da Espanha; Netherlands pib - PIB da Holanda;

Netherlands inf - inflação da Holanda; Portugal pib - PIB de Portugal; Portugal inf - inflação de Portugal; Austria pib - PIB da Áustria; Austria inf - inflação da Áustria; Slovak Republic pib PIB da Eslováquia; Slovak Republic inf - inflação da Eslováquia; Greece pib - PIB da Grécia; Greece inf - inflação da Grécia. 
Para avaliarmos a importância relativa do choque específico e do choque comum, adotamos um indicador cuja construção vamos explicitar a seguir. Seja: $E E_{i}=$ a mediana da banda de probabilidade do choque inicial (zero passo à frente) obtida da função impulso resposta do choque específico do país " $\mathrm{i}$; e $C C_{i}=$ a mediana da banda de probabilidade do choque inicial (zero passo à frente) obtida da função impulso-resposta do choque comum do país "i". Então o indicador para a importância do choque específico para o país "i" em relação ao choque comum é dada por $\left[\left(E E_{i} / C C_{i}\right)-1\right]^{*} 100$. Utilizando esse indicador alguns países se mostraram mais integrados (percentual menor de importância do choque específico em relação ao choque comum), dentre estes destacamos: Alemanha, Itália e Finlândia. Em contrapartida, alguns países se mostraram menos integrados (percentual maior de importância do choque específico em relação ao choque comum), com destaque para: Portugal, Grécia, Irlanda, França, Áustria, Estônia, Eslovênia e Luxemburgo. Parece existir um padrão no qual os países maiores são mais integrados, a exceção a essa regra é a França, um país grande que apresenta um choque específico relativamente importante quando comparado ao choque comum $(95 \%$ do choque comum). Em geral, os países menores parecem ser menos integrados, e a exceção é a Finlândia, que apresenta um choque específico relativamente pequeno quando comparado ao choque comum (70\% do choque comum).

Analisando as respostas do PIB de cada país a um choque específico e a um choque comum, constatamos que a resposta do PIB ao choque específico é menor que a resposta ao choque comum em todos os países, o que parece indicar uma integração entre eles. A magnitude da resposta dos países ao choque comum é maior do que a resposta dos países ao choque específico, o que endossa a existência de semelhança nos movimentos do produto na região. Quando avaliamos a importância relativa dos choques específico e comum podemos identificar quais países estão mais ou menos integrados entre si.

Um elemento central para a análise da integração na Zona do Euro é em que medida a resposta ao choque específico é menor (ou maior) que a resposta ao choque comum entre os países membros da UEM.

De acordo com a Figura 4, analisando as respostas aos choques específico e comum na região, as quatro maiores economias da UEM - Alemanha, França, Itália e Espanha - apresentam uma resposta ao choque específico menor que a resposta ao choque comum, o que parece indicar integração. Avaliando a importância relativa entre os choques específico e comum, quando comparamos a mediana da banda do choque inicial, identificamos que Alemanha, Itália e Espanha estão mais integrados, pois os dois primeiros apresentam $70 \%$ de importância relativa entre esses choques, e a Espanha apresenta 76\%. Cabe destacar que a França apresenta 95\% de importância relativa do choque específico em relação ao choque comum, o que indica que apesar de ser uma das maiores economias da Zona do Euro, o choque específico tem uma importância relativa relevante para explicar a flutuação do produto no país. Observouse ainda que a resposta ao choque comum se mostrou persistente nesses países, sobretudo na França e na Espanha.

Como mostra a Figura 5, a importância relativa dos choques específico e comum dos países mais integrados da Figura 4 é acompanhada de perto pela Finlândia (70\%), Bélgica (75\%) e Holanda (77\%).

Conforme a Figura 6, entre os países que se mostraram menos integrados temos: Irlanda, Grécia, Portugal, Chipre e Eslováquia. A importância relativa dos choques específico e comum nesses países foi de $82 \%$ na Irlanda, $83 \%$ na 
Figura 4: Choque específico e choque comum: Alemanha, França, Itália e Espanha
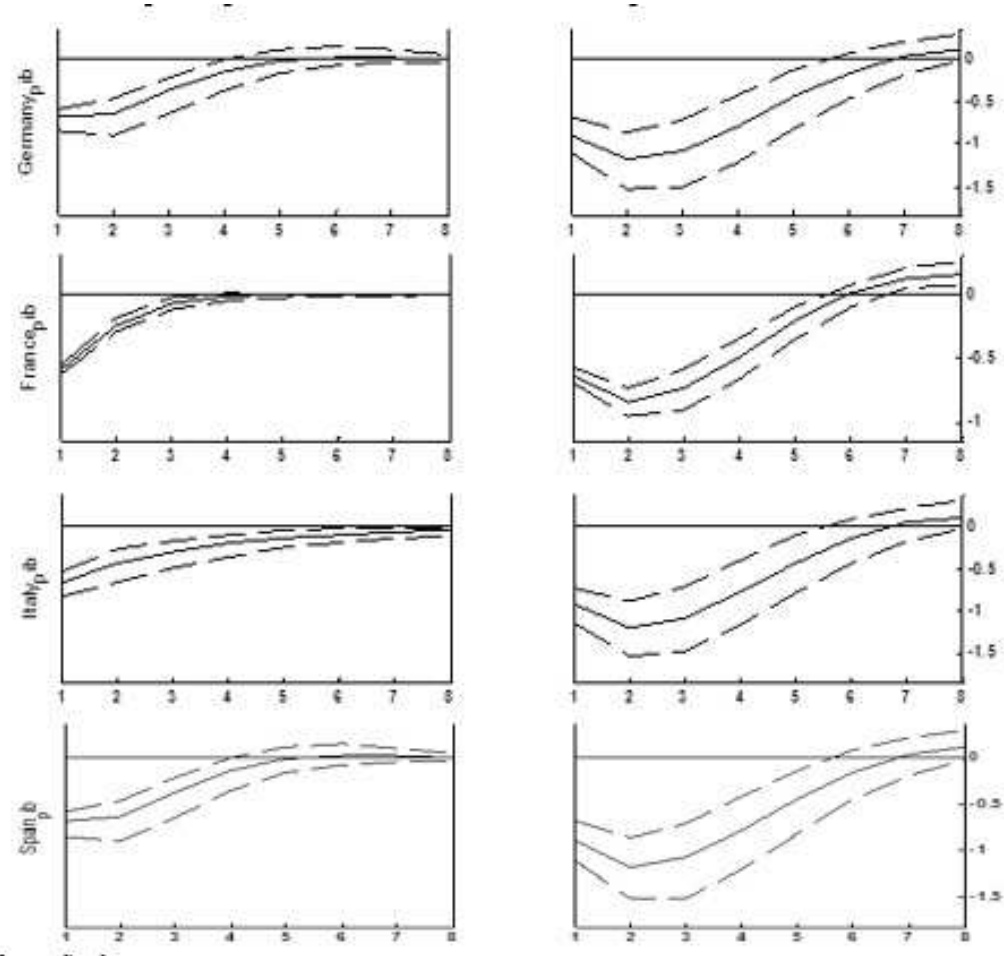

Fonte: Elaboração dos autores.

Legenda: Germany pib - PIB da Alemanha; France pib - PIB da França; Italy pib - PIB da Itália; Spain pib - PIB da Espanha.

Grécia, Portugal e Chipre e de $86 \%$ na Eslováquia.

De acordo com a Figura 7, entre os países ainda menos integrados entre os países analisados, temos: Estônia, Áustria, Luxemburgo e Eslovênia, conforme apresentado a seguir.

Com base nos resultados obtidos, as evidências empíricas parecem indicar que existe sincronia nos movimentos do produto e, portanto, integração entre os países membros da Zona do Euro, o que é justificado pelas respostas ao choque comum serem maiores que as respostas ao choque específico para todos os países membros da UEM.

Os países apresentados na Figura 7 se mostraram ainda menos integrados que os países da Figura 6, pois a importância relativa dos choques específico e comum foram de $90 \%$ para Estônia e Áustria, 93\% para Luxemburgo e 94\% para Eslovênia, o que parece sugerir que os países pequenos são menos integrados que os países grandes, com exceção da França, que é o segundo maior país da Zona do Euro, tanto em termos de população quanto de PIB, e apresenta uma importância relativa do choque específico alta em relação ao choque comum (95\%).

A partir da análise acima descrita, é notável que as respostas ao choque comum são maiores que as repostas ao choque específico para todos os países membros da UEM. O único país que não foi contemplado na análise foi Malta, pela escassez de dados desse país, que não permitiu que fossem gerados seus 
Figura 5: Choque específico e choque comum: Finlândia, Bélgica e Holanda
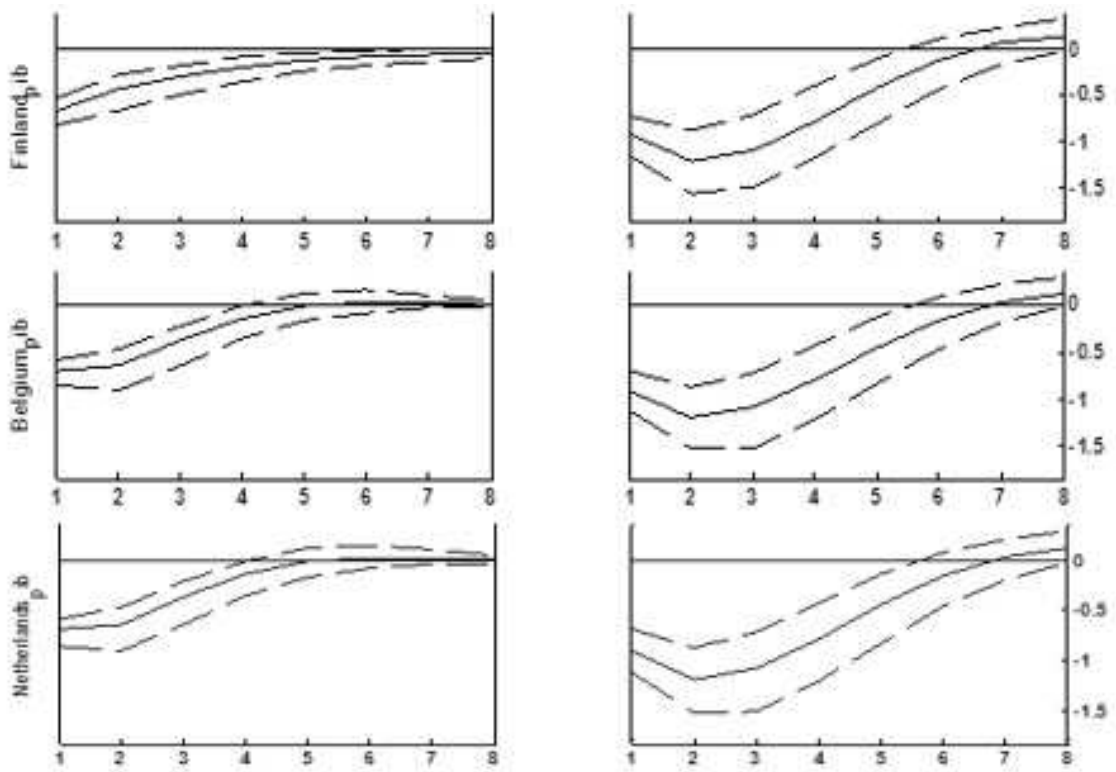

Fonte: Elaboração dos autores.

Legenda: Finland pib - PIB da Finlândia; Belgium pib - PIB da Bélgica; Netherlands pib - PIB da Holanda.

respectivos gráficos, correspondentes às respostas aos choques específico e comum.

A teoria econômica prediz que se a incidência de choques e a velocidade com que os países se ajustam a esses choques forem semelhantes entre os diversos países, como parece ser o caso dos países da Zona do Euro, então se reduz a necessidade de uma política monetária independente e diminui o custo de perder o controle direto sobre a taxa de câmbio nominal.

Traçando um breve comparativo dos resultados obtidos neste artigo, cuja análise compreende o período pós-UEM (1999-2013), com estudo anterior de Bayoumi \& Eichengreen (1992) e Eichengreen (1993), embora este último tenha adotado uma metodologia diferente da proposta no presente artigo e utilizado um período de análise pré-UEM (1960-1988), é possível apontar alguma similaridade: países identificados como de "centro" no estudo de Bayoumi \& Eichengreen (1992) e Eichengreen (1993), por caracterizarem regiões com um comportamento relativamente simétrico, à exemplo de Alemanha, Bélgica, Dinamarca e Holanda, mantêm o padrão de mostrarem-se mais integrados como no trabalho empírico realizado neste artigo, enquanto países apontados como "periferia" por Bayoumi \& Eichengreen (1992) e Eichengreen (1993), como Grécia, Irlanda e Portugal, assim denominados por esses autores por apresentarem respostas aos choques mais fracamente correlacionados com os experimentados pelo "centro", mostraram-se também no período aqui analisado menos integrados. 
Figura 6: Choque específico e choque comum: Irlanda, Grécia, Portugal, Chipre e Eslováquia

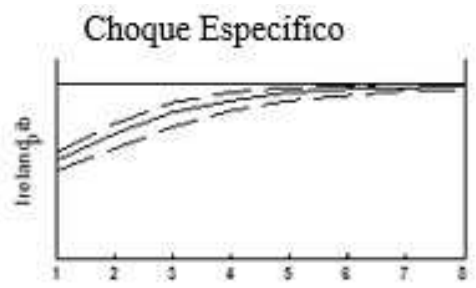

\section{Choque Comum}
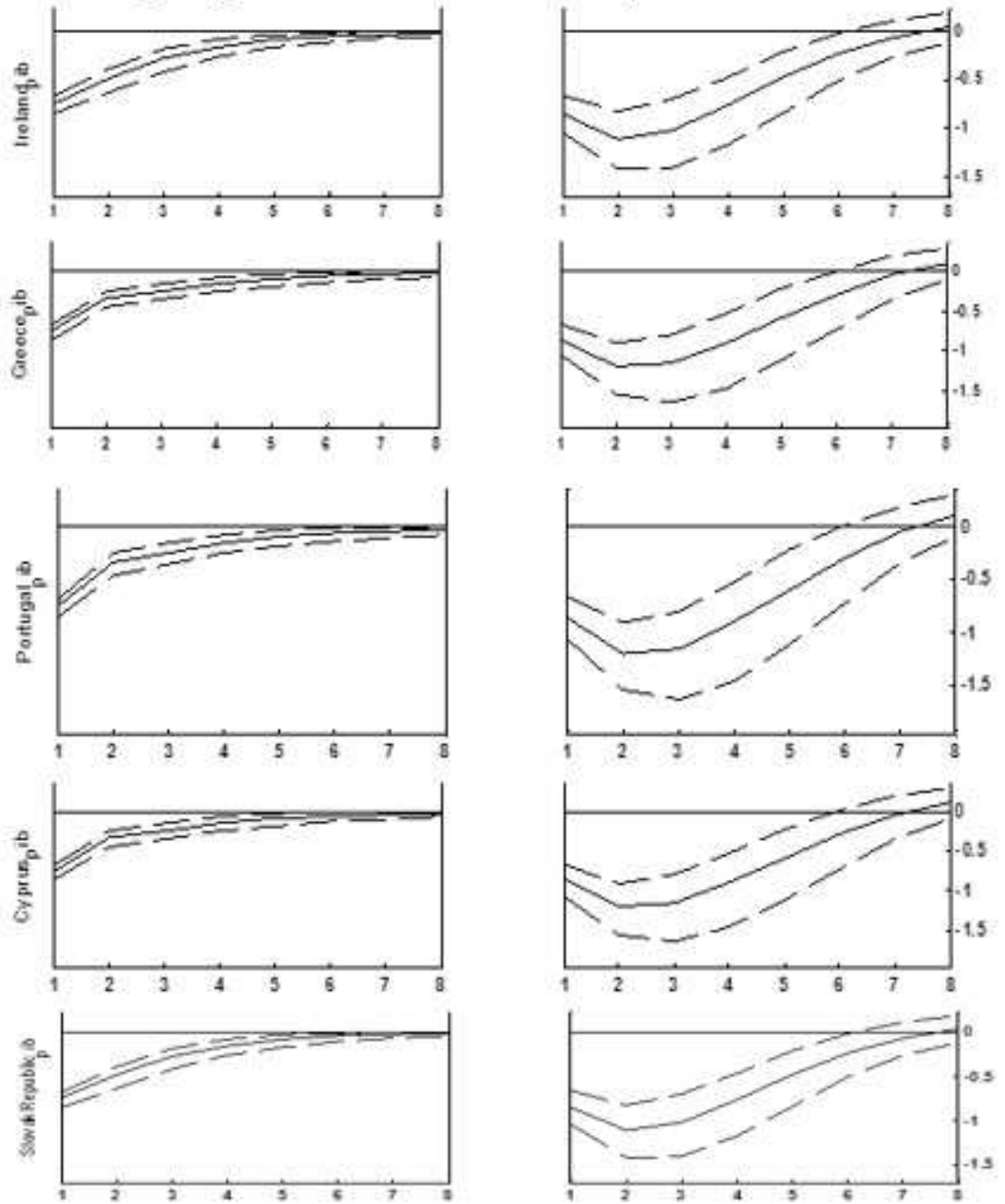

Fonte: Elaboração dos autores.

Legenda: Ireland pib - PIB da Irlanda; Greece pib - PIB da Grécia; Portugal pib - PIB de Portugal; Cyprus pib - PIB de Chipre; SlovakRepublic pib - PIB da Eslováquia. 
Figura 7: Choque específico e choque comum: Estônia, Áustria, Luxemburgo e Eslovênia
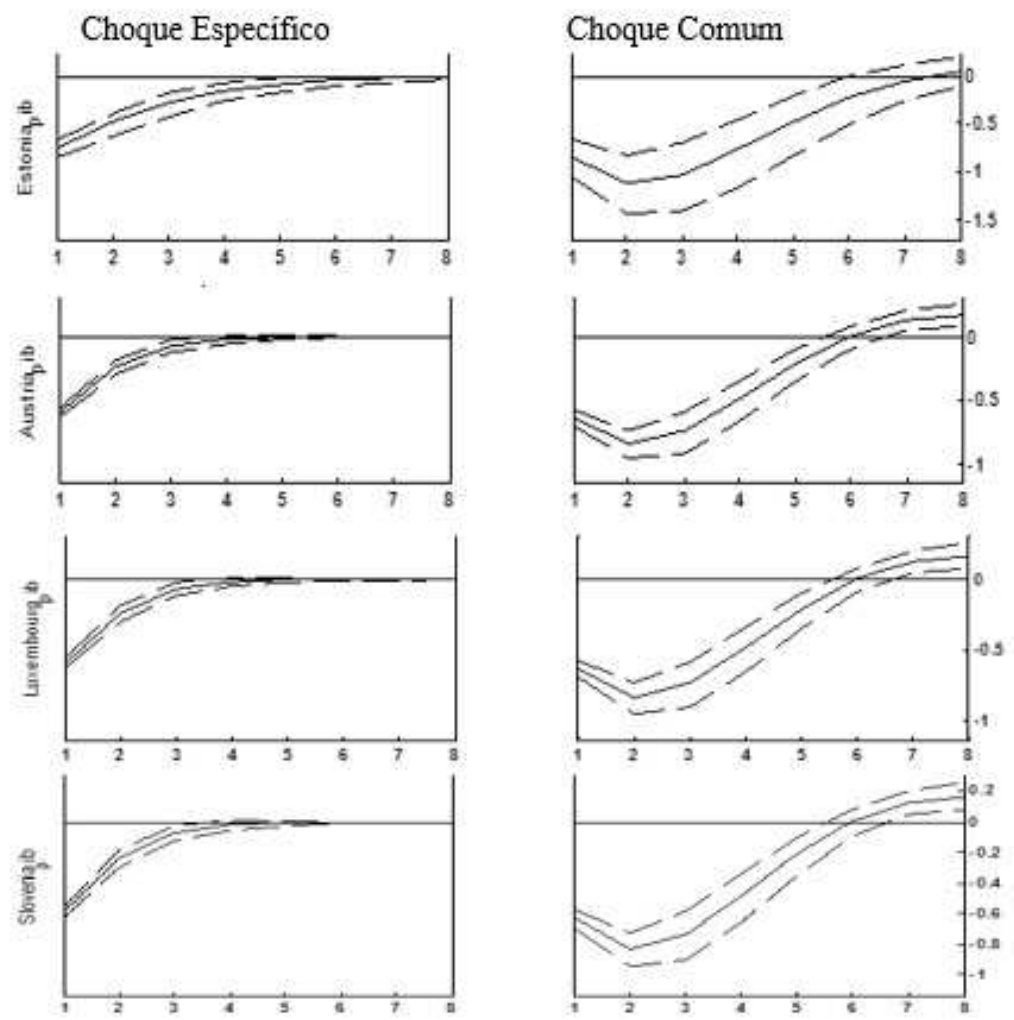

Fonte: Elaboração dos autores.

Legenda: Estonia pib - PIB da Estônia; Austria pib - PIB da Áustria; Luxembourg pib PIB da Luxemburgo; Slovenia pib - PIB da Eslovênia.

\section{Conclusão}

Este artigo realizou uma avaliação empírica da semelhança de choques na Zona do Euro. Inicialmente, foi feita uma resenha da literatura empírica sobre sincronização de ciclos econômicos na Zona do Euro, cujos resultados variam muito dependendo do período de análise observado. Enquanto estudos realizados nos períodos pré-UEM e subsequentes à formação da união monetária encontraram pequena evidência de convergência entre o "centro" e a "periferia" da região ao longo do tempo e apontaram para heterogeneidade dos movimentos de produto e preço entre os países da região, um estudo mais recente (Bernanke et al. 2005) mostra que a criação do Euro tem contribuído para uma maior homogeneidade nos mecanismos de transmissão da política monetária entre os países membros da UEM e para uma redução generalizada nos efeitos desses choques.

Na sequência, foi realizada uma análise empírica com o objetivo de investigar a importância relativa dos choques específico e comum entre os países membros da Zona do Euro e obter a resposta desses países a esses choques, a fim de avaliar a integração desses países com a UEM. Além disso, foram feitos outros dois exercícios: um choque contracionista de política monetária e um 
choque de desvalorização do Euro, e avaliou-se a resposta dos mesmos entre os países da UEM. Para executar esses testes, foi utilizado um Vetor Autorregressivo Aumentado por Fatores Dinâmicos (FAVAR), utilizando a informação contida em um amplo conjunto de variáveis econômicas e financeiras dos 17 países membros da Zona do Euro.

Verificou-se no exercício empírico, que o choque contracionista de política monetária apresentou resposta semelhante, ou seja, queda da inflação e do produto nos seguintes países: Alemanha, Bélgica, Espanha, França, Holanda, Irlanda, Itália e Luxemburgo. Portugal apresentou resposta apenas sobre o nível de preços, com queda da inflação. Alguns países apresentaram resposta só de desaceleração econômica, com queda do produto, foram eles: Áustria, Estônia, Eslovênia, Eslováquia, Finlândia e Grécia. Para os demais países (Chipre e Malta), não houve resposta significativa nem da inflação nem do nível de atividade. Os choques identificados de política monetária, na Zona do Euro, apresentam respostas (quando significativas) com os sinais esperados, mas que não são estritamente iguais (homogêneas) entre os países.

Considerando um choque exógeno de desvalorização do Euro, Alemanha, Bélgica, Espanha, Eslovênia, França, Finlândia, Irlanda, Itália, Luxemburgo, Holanda e Portugal apresentaram resposta semelhante, a saber, aumento do nível do produto e da inflação. Áustria, Estônia e Eslováquia apresentaram apenas aumento do nível do produto. Grécia apresentou apenas aumento da inflação. Os demais países não apresentaram resposta significativa.

O resultado do exercício empírico realizado parece indicar a existência de sincronia nos movimentos do produto e, portanto, de uma tendência de integração entre os países membros da Zona do Euro, o que é identificado pelas respostas ao choque comum serem maiores do que as respostas ao choque específico para todos os países da UEM. Os resultados obtidos podem se revelar contraintuitivo, uma vez que a princípio uma das facetas que a crise do Euro revelaria seria justamente a falta de sincronia nos movimentos do produto entre os países membros, além do fato de que os países tenderiam a ter respostas diferenciadas a choques da política monetária e choques da taxa de câmbio. Evidentemente, o assunto requer um aprofundamento, com realização de outros exercícios empíricos, inclusive com uso de outros instrumentais econométricos, para verificar se os resultados são robustos. Uma sugestão para futuras pesquisas empíricas é fazer uma segmentação da amostra - antes e depois da formação da UEM - como o intuito de realizar uma análise estática comparativa e avaliar melhor a sincronização dos movimentos do produto na Zona do Euro.

Contudo, uma hipótese que poderia ser levantada é que o problema do Euro não está necessariamente na falta de convergência econômica ou na menor integração entre os países da região, mas sim nas falhas no desenho da governança da política econômica, dada a restrição (até recentemente) de o Banco Central Europeu atuar como emprestador de última instância do sistema financeiro, a falta de uma união fiscal mais efetiva e a ausência de um verdadeiro governo central na comunidade Europeia De Grauwe (2013). Isso tem feito com que a capacidade de as autoridades econômicas responderem aos desafios colocados pela crise seja bastante restrita e lenta, o que faz com que os problemas econômicos da região acabem por se agravar. 


\section{Referências Bibliográficas}

Almeida, G., Alves, P. \& Lima, E. (2012), Impactos dos choques na política monetária e no câmbio no Brasil: um modelo de autorregressão vetorial estrutural aumentada por fatores dinâmicos. Texto para Discussão n. 1711, Rio de Janeiro, IPEA.

Artis, M. (1991), 'One market, one money: an evaluation of the potential benefits and costs of forming an economic and monetary union', Open Economies Review 2(3), 315-321.

Barro, R. \& Gordon, D. (1983), 'Rules, discretion and reputation in a model of monetary policy', Journal of Monetary Economics 12, 101-121.

Baxter, M. \& Kouparitsas, M. (2005), 'Determinants of business cycles comovements: a robust analysis', Journal of Monetary Economics 52, 113-157.

Bayoumi, T. \& Eichengreen, B. (1992), Shocking aspects of European monetary unification. NBER Working Paper n. 3949.

Bernanke, B. S., Boivin, J. \& Eliasz, P. (2005), 'Measuring monetary policy: a Factor Augmented Vector Autoregressive (FAVAR) approach', Quarterly Journal of Economics 120(1), 387-422.

Boivin, J., Giannoni, M. P. \& Mojon, B. (2008), How has the Euro changed the monetary transmission? NBER Working Paper n. 14190.

Buiter, W. (1995), Macroeconomic policy during the transition to monetary union. CEPR Discussion Paper 1222.

Carter, C. K. \& Kohn, R. (1994), 'Gibbs sampling for state space models', Biometrica 81(3), 541-553.

Clark, T. E. \& Wincoop, E. (2001), 'Borders and business cycles', Journal of International Economics 55, 59-85.

De Grauwe, P. (1992), The Economics of Monetary Union, Oxford University Press.

De Grauwe, P. (2013), Design failures in the Eurozone: can they be fixed? LSE ‘Europe in Question’ Discussion Paper Series n. 57.

ECB (2013), 'European Central Bank'. Acesso em 22 de julho de 2013.

URL: $h t t p: / / w w w . e c b . i n t / s t a t s / m o n e t a r y / r a t e s / h t m l / i n d e x . e n . h t m l$

Eichengreen, B. (1993), 'European monetary unification', Journal of Economic Literature 31, 1321-1357.

Eickmeier, S. (2006), Co-movements and heterogeneity in the Euro area analyzed in a non-stationary dynamic factor model. Bundesbank Discussion Paper 31.

EUROSTAT (2013). Acesso em 09 de agosto de 2013.

URL: epp.eurostat.ec.europa.eu/portal/page/portal/statistics/search_database

FED (2013), 'Federal Reserve'. Acesso em 22 de julho de 2013.

URL: $h t t p: / / w w w . f e d e r a l r e s e r v e . g o v / m o n e t a r y p o l i c y / o p e n m a r k e t . h t m$ 
Frankel, J. \& Rose, A. (1998), 'The endogeneity of the optimum currency area criteria', Economic Journal 108, 1009-1025.

Gamerman, D. (1996), Simulação estocástica nas cadeias de Markov, in 'Caxambu, Associação Brasileira de Estatística'.

Gonçalves, C. E., Rodrigues, M. \& Soares, T. (2009), 'Correlation of business cycles in the euro zone', Economics Letters 102, 56-58.

IMF (2013), 'International monetary fund'. Acesso em 10 de agosto de 2013. URL: http://www.imf.org/external/data.htm

Kenen, P. (1969), The theory of optimum currency areas: an eclectic view, in R. Mundell \& A. K. Swoboda, eds, 'Monetary Problems of the International Economy', Chicago, University of Chicago Press, pp. 41-60.

Krugman, P. (1993), Lessons from Massachusetts for EMU, in F. Torres \& F. Giavazzi, eds, 'Adjustment and Growth in the European Monetary Union', Cambridge, Cambridge University Press, pp. 241-260.

Kydland, F. \& Prescott, E. (1977), 'Rules rather discretion: the inconsistency of optimal plans', Journal of Political Economy 85(3), 473-491.

Lima, E., Maka, A. \& Alves, P. (2011), 'Monetary policy and exchange rate shocks in Brazil: sign restrictions versus a new hybrid identification approach', Brazilian Review of Econometrics 31(1), 97-136.

Litterman, R. (1986), 'Forecasting with Bayesian vector autoregressions five years of experience', Journal of Business and Economic Statistics 4(1), 25-38.

McKinnon, R. (1963), 'Optimum currency areas', The American Economic Review 53, 717-725.

Mundell, R. (1961), 'A theory of optimum currency areas', The American Economic Review 51, 657-665.

OECD (2013), 'The organization for economic cooperation and development'. Acesso em 21 de julho de 2013.

URL: http://www.oecd.org

Rogoff, K. (2001), 'On why not a global currency', American Economic Review Papers and Proceedings 91, 243-247.

Stock, J. H. \& Watson, M. W. (1999), 'Forecasting inflation', Journal of Monetary Economics 44(2), 293-335.

Tavlas, G. (1993), 'The 'new' theory of optimum currency areas', The World Economy 16, 663-685.

Waggoner, D. \& Zha, T. (2003), 'A Gibbs simulator for restricted VAR models', Journal of Economic Dynamics and Control 26, 349-366.

\section{Apêndice A}


Tabela A.1: Resultados dos testes de raíz unitária Phillips-Perron

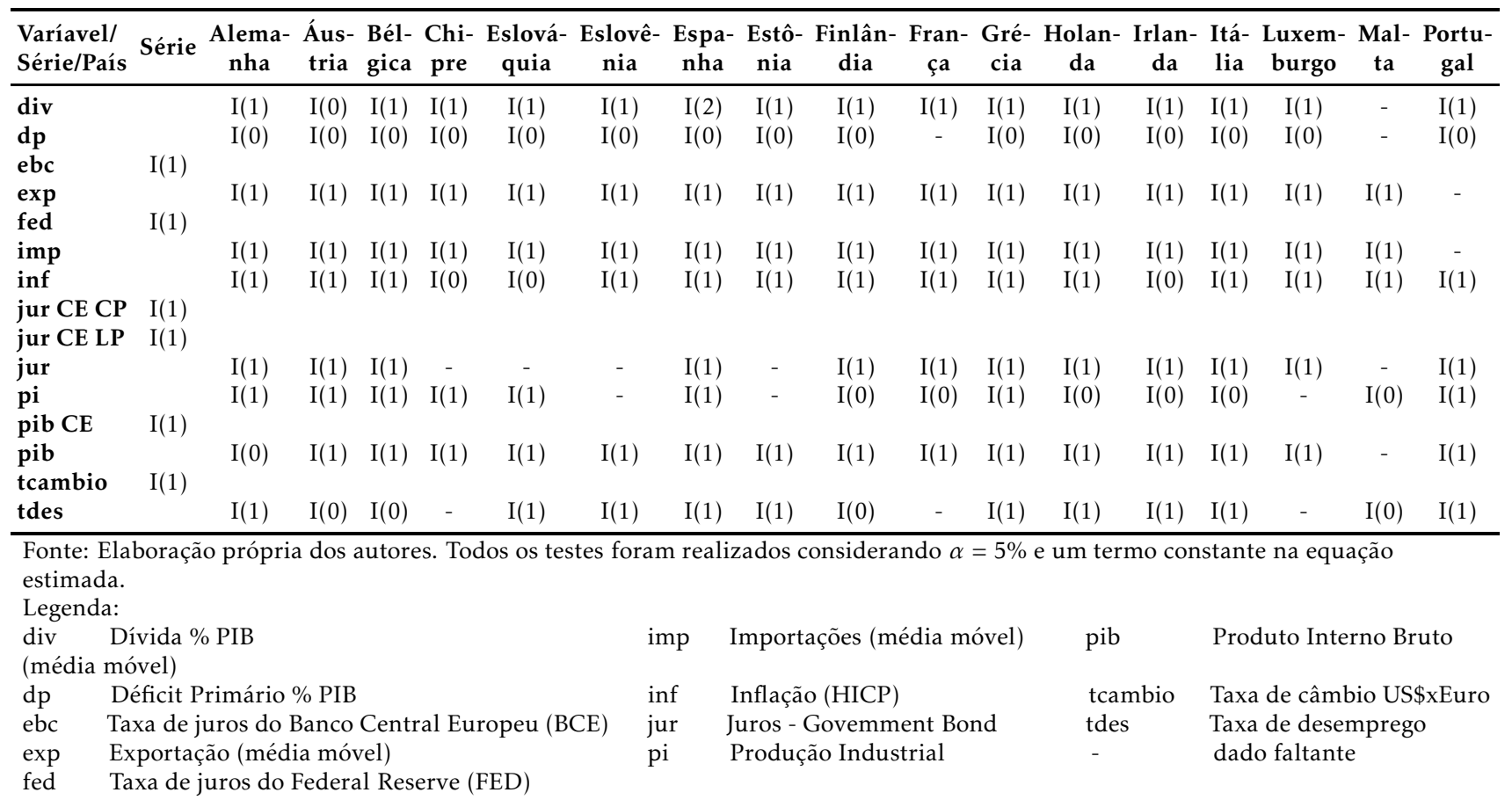


